\section{MRS FAQs \\ (MRS Frequently Asked Questions)}

In January, when you receive this latest copy of MRS Bulletin, I will formally be the Materials Research Society's 28th president. Usually the first letter from the new president is full of sincere offers of openness, accessibility, and accountability. It inevitably ends with a call to all members to phone, e-mail, or write with their urgent concerns. And, each year, exactly one person writes in response to this letter. Usually it is one of the previous past presidents who, having gone through this ritual, takes knowing pity on the idealism of the newly elected officer.

But, having occupied the halls of MRS most of my professional life, I can venture a guess as to what a good fraction of the un-uttered questions might be. They are the Old Faithfuls, the swallows of Capistrano, the recurring issues that come home to MRS year after year after year in committee meetings, symposium organizer wrap-up meetings, and poster sessions. So, in advance of their yearly appearance this year, here they are: the four most common MRS FAQs.

4 Why does MRS publish proceedings? They don't count for anything in the tenure process.

$\mathrm{O}$, ye of academia. It is absolutely true that most U.S. professors do not receive "credit" for publishing in a proceedings. It is also absolutely true that not everyone is a U.S. professor. Authors from emerging nations use the Proceedings to reach a global audience. Graduate students use them as a comprehensible digest of the latest advances in the field they are trying to learn. Industry members use them in lieu of the library their company does not have. And many national laboratory employees do get at least partial credit in their annual review cycle for publishing in the MRS proceedings. In fact, MRS polls show that nearly $80 \%$ of symposium attendees want to publish in a proceedings, and about $50 \%$ end up doing so. Data on circulation rates of the proceedings within academic libraries also show that they are heavily used. We have a diverse membership, and our Proceedings serve a significant segment of this membership.

Not insignificantly, in my view, the Proceedings are also one of the two MRS endeavors that actually makes a sizeable net profit. The other is the equipment exhibit at MRS meetings. The MRS Proceedings therefore subsidize many other activities, like the Web site, that would otherwise be economically impossible. Of

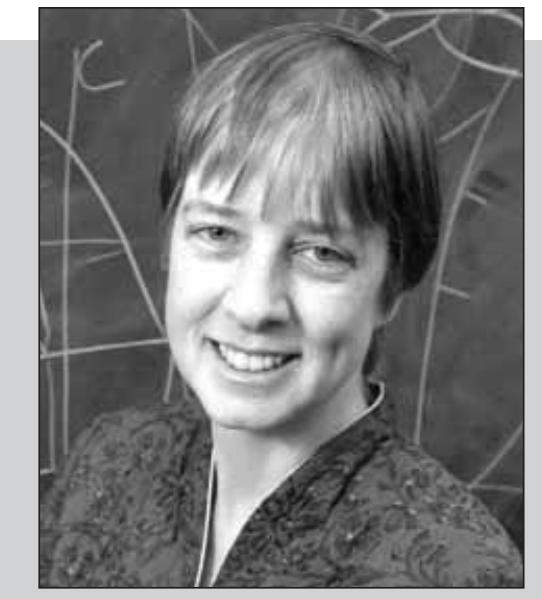

"In our current rate structure, our membership fees are set to be exactly break-even."

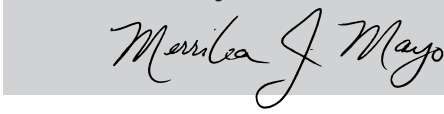

course, there are improvements to be made: We are still trying to find a way to get the Proceedings cited by ISI.

Why is it that MRS membership costs $\$ 100$ and I get only the MRS Bulletin, while membership in Society X is $\$ 100$ and I get their membership magazine, their full article journal, their letters journal, reduced conference registration rates, life insurance, auto insurance, a Visa card, and a free pen set?

We do significant benchmarking against other professional societies-largely those in the materials arena-and we have yet to find the mysterious Society $X$. The closest thing seems to be the Electrochemical Society, where one can get the full journal series, access to the electronic letters journal, and the membership magazine for $\$ 90$. I intend to look into this one carefully, to see if we can learn from some possible structural differences. In our current rate structure, our membership fees are set to be exactly break-even. For the $\$ 100$ at MRS, you not only receive the MRS Bulletin but online access to hundreds of MRS Proceedings, reduced registration rates at the meetings, and reduced subscription rates to not only the Journal of Materials Research, but also several AIP journals (such as Applied Physics Letters, Journal of Applied Physics, The Journal of Chemical Physics, and 25 others). One very unusual feature of MRS is that registering for a meeting automatically makes you a member-for free. If we were to decouple membership from meeting registration, it may be that we could support more membership benefits than we currently do.

2 Why do we always have the MRS Meetings in San Francisco and Boston. It would be cheaper if they were held in a smaller city!!!!

This is one of those issues where you just aren't going to satisfy everybody. Polls of MRS members show that $1 / 3$ adore San Francisco and Boston and are strongly in favor of keeping the meetings there, $1 / 3$ really don't care where the meeting is, and $1 / 3$ are vocally in favor of moving the meeting to a cheaper city (cities in the Midwest are often cited). If the membership itself could come to a clear majority in favor of a move, MRS would respond accordingly. However, with the membership strongly divided, and at opposite poles, it does not make sense to absorb the energy and cost of negotiating a move to a new city. As a final and intriguing note, we did look at how attendance patterns at other societies' annual meetings varied, depending on the city in which the meeting was held. Mostly attendance was insensitive to the host city; however, cities in the southern Midwest (such as St. Louis and Kansas City) suffered significant attendance losses.

Why are MRS Meetings always the week after Thanksgiving and the week after Easter? I don't like having to travel right after (sometimes during) a holiday weekend.

I really don't either. The reason MRS has its meetings at these times is precisely because no one likes to travel these weeks. They are the lowest travel times of the year. Consequently, the room rates for the meeting are $\$ 50-\$ 80$ cheaper per night than they would be if the meeting were moved even one week in either direction. An elegant solution to the holiday dilemma was (re)implemented by the Meeting Chairs of Spring 2001, who shifted the whole Spring Meeting one day forward, so it began the Tuesday following Easter and extended through Friday, rather than starting on Monday and ending Thursday as it had done for the previous 12 years. This oneday shift meant that meeting attendees no longer had to actually travel on the holiday weekend. A similar solution for the Fall Meeting is being discussed, but it is much harder to implement because the Fall Meeting occupies many more symposium days and takes most of a full week.

MERRILEA J. MAYO 2003 MRS President 